\title{
Serum antibodies to Trichomonas vaginalis in invasive cervical cancer patients
}

\author{
E H Yap, T H Ho, Y C Chan, T W Thong, G C Ng, L C Ho, M Singh
}

\begin{abstract}
Objective-To evaluate, by seroepidemiology, the possible role of the sexuallytransmitted flagellate, Trichomonas vaginalis, in invasive cervical cancer.
\end{abstract}

Subjects and method-Sera from 121 invasive cervical cancer patients and 242 random age-matched female controls. Antibodies to $T$. vaginalis were detected by the western blot technique.

Results-Antibodies to $T$. vaginalis were detected in the sera of $41 \cdot 3 \%(50 / 121)$ of invasive cervical cancer patients compared with only $5 \cdot 0 \%(12 / 242)$ of female controls. All the reactive sera reacted strongly with the immunogenic surface membrane proteins of $T$. vaginalis of molecular weights of about 92 and 115 $\mathrm{kDa}$, with variable reactivity to other immunogenic proteins of $T$. vaginalis. Conclusion-The significantly increased relative risk, $R R=3.42(95 \%$ CI $=$ 1.73-6.78), is comparable to the RRs derived in seroepidemiological studies of human papillomavirus, suggesting that $T$. vaginalis may be even more closely associated with invasive cervical cancer than previously realized.

(Genitourin Med 1995;71:402-404)

Keywords: Trichomonas vaginalis, Antibodies, Cervical cancer

\section{Introduction}

Cervical cancer is one of the most common malignant diseases worldwide. The epidemiological profile suggests that the aetiological agent/s are genital pathogens, probably acting synergistically. ${ }^{1}$ Many sexually-transmitted organisms have been associated with it, principally human papillomavirus (HPV), herpes simplex virus (HSV) type-2 and Chlamydia trachomatis. Current evidence tends to support a causal role of high risk oncogenic HPV types in cervical cancer, although only a small number of those with HPV infection develop invasive cervical cancer. In the island republic of Singapore where about 200 cases of cervical cancer are reported annually, we have found that $95 \cdot 1 \%$ of biopsies from patients contained HPV 16 and/or 18 DNA. ${ }^{2}$ A possible association of Trichomonas vaginalis, a sexuallytransmitted parasite, with cervical cancer was reported in $1969 .{ }^{3,4}$ In the present study, we report the high prevalence of antibodies to $T$. vaginalis in the sera of patients with invasive cervical carcinoma compared with that of healthy female controls, and discuss the possi ble role of $T$. vaginalis in cervical cancer.

\section{Materials and methods}

Sera were obtained from 121 invasive cervica cancer patients at the Singapore Generat Hospital during the period 1987-1989, and from 242 local age-matched healthy adult females. Sera were stored at $-70^{\circ} \mathrm{C}$ Antibodies were detected by the western blo? technique ${ }^{5}$ using antigen prepared by th\& trichloroacetic acid-precipitation ${ }^{6}$ of ars axenized local isolate of $T$. vaginalis cultured in Hollander medium. ${ }^{7}$ Briefly, the antigen was electrophoresed in a $10 \%$ SDS-PAGE gel After blotting, the nitrocellulose was placed in blocking solution made up of 5\% non-fat skin milk for $1 \mathrm{~h}$ at $37^{\circ} \mathrm{C}$. After incubation overnight in a 1:50 dilution of the humaref serum, the nitrocellulose was washed twice for $10 \mathrm{~min}$ each with Tris-buffered saline- $0.05 \%$ Tween 20. Following washing, a 1:200 dilu tion of rabbit antihuman IgG, IgA, IgM, con jugated to horseradish peroxidase (DAKO was added and incubated at $37^{\circ} \mathrm{C}$ for $1 \mathrm{~h}$

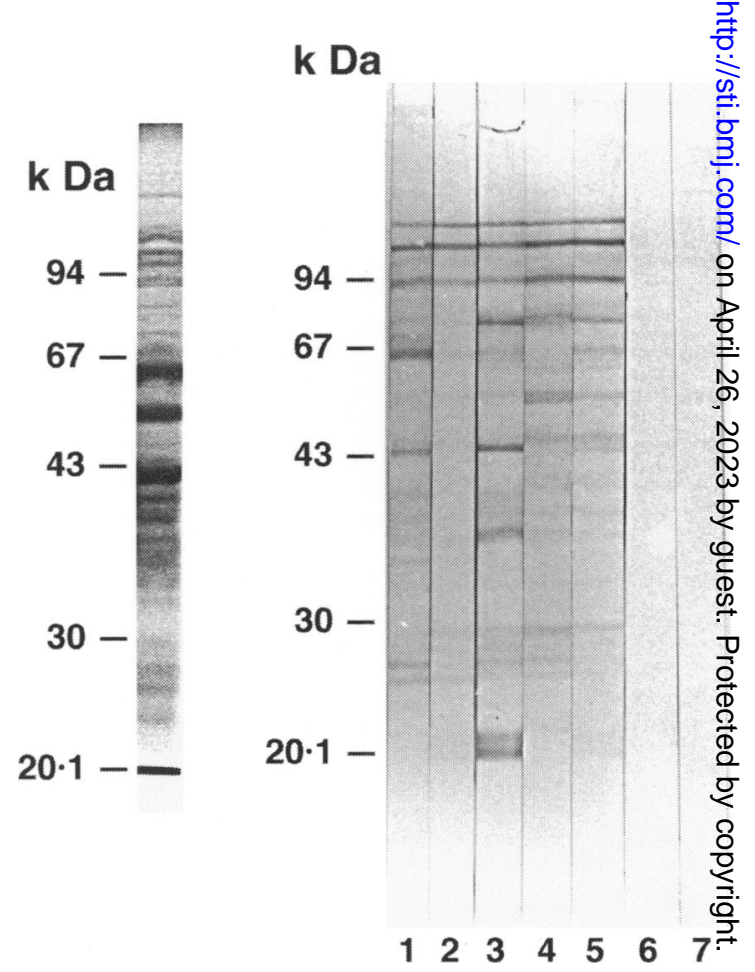

(Left) Coomassie brilliant blue-stained SDS-PAGE of trichloroacetic acid-precipitated $T$. vaginalis.

(Right) Western blot of serum antibodies to $T$. vaginalis in patients with cervical cancer (Lanes 1-5) and in normal female controls (Lanes 6-7). 
Table Western blot analyses of serum antibodies to $T$. vaginalis in cervical cancer patients and age-matched female controls

\begin{tabular}{lccccccccc}
\hline & \multicolumn{1}{l}{ Age group $(y r)$} & & & & \\
\cline { 2 - 9 } T. vaginalis antibodies in & $20-29$ & $30-39$ & $40-49$ & $50-59$ & $60-69$ & $70-79$ & $\geqslant 80$ & Total \\
\hline Cervical cancer patients & $1 / 2$ & $8 / 16$ & $8 / 22$ & $17 / 40$ & $10 / 24$ & $6 / 12$ & $0 / 5$ & $50 / 121$ \\
(Percentage positive) & $50 \cdot 0$ & $50 \cdot 0$ & $36 \cdot 4$ & $42 \cdot 5$ & $41 \cdot 7$ & $50 \cdot 0$ & 0 & $41 \cdot 3$ \\
Age-matched controls & $0 / 4$ & $1 / 32$ & $2 / 44$ & $6 / 80$ & $2 / 48$ & $1 / 24$ & $0 / 10$ & $12 / 242$ & $5 \cdot 0$ \\
(Percentage positive) & 0 & $3 \cdot 1$ & $4 \cdot 6$ & $7 \cdot 5$ & $4 \cdot 2$ & $4 \cdot 2$ & 0 & $5 / 0$ \\
\hline
\end{tabular}

After washing, the nitrocellulose was developed in $0.015 \% \mathrm{H}_{2} \mathrm{O}_{2}$ and 4-chloro-1-naphthol.

\section{Results}

Figure shows the Coomassie brilliant bluestained SDS-PAGE profile of the trichloroacetic acid-precipitated $T$. vaginalis. By western blot analyses, it was found that there was more than eight-fold increase $(41.3 \%$ vs $5.0 \% ; \mathrm{RR}=3.42 ; 95 \% \mathrm{CI}=$ 1.73-6.78) in prevalence of antibodies to $T$. vaginalis in Singapore patients with invasive cervical cancer compared with healthy agematched female controls (table). The increase was evident in all age groups from 20-79 years, except those in the cohort $\geqslant 80$ years old. Using the same technique, we had also found that a high percentage, $58.9 \%(33 / 56)$, of sera from patients with cervical cancer in Thailand had antibodies to $T$. vaginalis. This data was not included in the table because no control serum was available. All the reactive sera from Singapore and Thailand reacted with $T$. vaginalis surface antigens of about MW 92 and $115 \mathrm{kDa}$, with variable reactivities against other antigens ranging from about 23 to $65 \mathrm{kDa}$ (figure). Antibodies to $T$. vaginalis were not detectable in normal and patient sera of those who were 80 years or older.

\section{Discussion}

This is the first seroepidemiological study demonstrating a significant association of $T$. vaginalis with invasive cervical cancer. The significantly increased relative risk $(R R=3.42)$ obtained in our study is of the same order as that derived in similar studies for HPV and cervical cancer where the RRs of $3 \cdot 1$ (for IgG to HPV 16- or 18-derived antigens from the L1 reading frame), $2 \cdot 8$ (for antigen from E2) and 3.8 (for antigens from E7) had provided further seroepidemiological support for an aetiological role of HPV in cervical cancer. ${ }^{8}$ In the same study, an increased risk was also found for IgG to Chlamydia trachomatis albeit with a low RR of $1.7(95 \% \mathrm{CI}=1 \cdot 0-2 \cdot 7)$, but antibodies against cytomegalovirus, HSV type-2, Epstein-Barr virus or bovine papillomavirus were, on their own, not significantly associated with cervical cancer.

In Singapore, the prevalence of $T$. vaginalis infection is relatively low, being isolated in only $3.5 \%(3 / 85)$ of patients attending a local STD clinic. ${ }^{9}$ This compares favourably with the $5.0 \%$ of our random female controls who had antibodies to this parasite. In contrast, a significant $43 \cdot 1 \%$ of our patients with cervical cancer had detectable antibodies by immunoblot, suggesting exposure to $T$. vaginalis. Patients with negative immunoblots could have been previously infected with the organism since serum antibodies to this genital pathogen is not likely to persist for very long. Host plasma proteins are able to bind avidly to live parasites, providing a mechanism by which the trichomonads might evade immune surveillance mechanisms occurring in the urogenital environment. ${ }^{10}$

During 1964-1966, in the Swedish county of Ostergotland, the frequency of $T$. vaginalis, in a series of more than 13,000 normal women, was found to be $7 \cdot 4 \%{ }^{3}$ There were 348 cases of pre-invasive and 47 of invasive cervical carcinoma. The frequencies of $T$. vaginalis in these cases were $29 \cdot 3 \%$ and $29 \cdot 8 \%$ respectively-values that were about 4 times that for the normal series. In Maryland, USA, studies involving a series of women with $T$. vaginalis, showed that "abnormal cytologic findings" were twice as common and the frequency of cervical carcinoma nearly 3 times as high as for subjects with smears negative for the species. ${ }^{11} \mathrm{~A}$ similar observation was made in Quebec, Canada, where cytologic diagnosis revealed that $27 \cdot 5 \%(36 / 131)$ of invasive cervical cancer patients had $T$. vaginalis compared with $10 \cdot 5 \%(6,528 / 62,284)$ of the normal female population. ${ }^{4}$ Recently, in Italy, it was reported that there was a markedly increased frequency of $T$. vaginalis in patients of cytological class III and IV according to the Papanicolaou classification. ${ }^{12} T$. vaginalis was also found with a more significant frequency in patients showing erosion of the cervix. Is it possible that the disintegrating cancer tissue favours growth of the trichomonad?

The above studies diagnosed $T$. vaginalis using cytologic, direct wet mounts and by culture of vaginal materials which reflect active infection. Serological diagnosis better reflect past as well as present infection, although the persistence of serum antibodies may be variable. That sera from two of our local patients with active trichomoniasis showed weak reactions in immunoblots compared to that seen in sera from the cervical cancer patients led us to believe that $T$. vaginalis may play a more active role than previously believed. The serum antibodies in our study reacted strongly with the immunogenic surface membrane proteins of $T$. vaginalis of molecular weights of about 92 and $115 \mathrm{kDa}$, with variable reactivity to other immunogenic proteins. These results support an earlier observation that different individuals respond immunologically to different $T$. vagi- 
nalis antigens. ${ }^{6}$ The high-titre antibodies reflect active invasion by the parasite which may promote malignancy. $T$. vaginalis exists in two forms, the ovoid-motile (OM) form and its variant, the amoeboid-adherent (AA) form. ${ }^{13}$ The cytotoxic AA form predominates in fresh cultures. In contrast, $T$. vaginalis maintained for years in axenic cultures tend not adhere to the epithelial cell monolayer, being cytotoxic at a concentration 100 times that of freshly-isolated trichomonads. ${ }^{14}$ Pathogenic $T$. vaginalis, but not the non-pathogenic $T$. tenax, selectively binds chemically stabilized HeLa cells which were originally derived from a cervical cancer patient! ${ }^{15}$ Binding involves at least 4 proteins of molecular weights ranging from 65 to $\leqslant 21 \mathrm{kDa}$. Not only are $T$. vaginalis able to adhere to cells, it has been observed to invade cells in a tissue biopsy of the cervix uteri. ${ }^{16}$ The cytopathic effect of $T$. vaginalis is mediated by close contact between the parasite and the epithelial surface with the release of substances such as the "cell-detaching factor" $(\mathrm{CDF}){ }^{17}$ and a variety of proteinases including metalloproteinases ${ }^{18}$ which is important in the progession of squamous cell carcinomas and metastasis. ${ }^{19}$

Live $T$. vaginalis has also been found to induce immunosuppression with the more pathogenic strains inducing a greater degree of immunosuppression. ${ }^{20}$ This could lead to activation of carcinogenic viruses. Large numbers of the flagellate could alter the microenvironment and facilitate the growth of facultative and anaerobic bacteria which may explain the equivocal association of some bacteria with cervical cancer. ${ }^{21}$

A likely role for $T$. vaginalis is that of a vector for the spread of other pathogens since reovirus and genital HSV have been found to be able to survive intracellularly but not Mycoplasma, Neisseria or Chlamydia. ${ }^{22,23}$ Unique non-segmented double-stranded RNA virus-like particles (VLPs) have been described in some isolates of $T$. vaginalis. ${ }^{24}$ The viral genome does not share significant homology with that of viruses of other parasites. Whether these VLPs have a role to play in cervical cancer may prove to be an intriguing investigation, although virus-harbouring trichomonads synthesize lower amounts of adhesins essential for the binding to target cells, hence are less adherent and correspondingly less cytotoxic to HeLa cells in vitro. ${ }^{25}$ The association, if any, between $T$. vaginalis and HPV, remains to be determined since their relative risks (RR) with cervical cancer are comparable. Whether $T$. vaginalis is merely a surrogate marker of exposure to HPV, influenced by promiscuous sexual behaviour which has been the most consistent epidemiological finding, ${ }^{26}$ is a moot point. After all, a close association between $T$. vaginalis infection and presence of vaginal papillomas had been reported. ${ }^{27}$

A possible application of our study would be to identify women with serum antibodies to $T$. vaginalis as being at higher risk of developing cervical cancer. A prospective study can be initiated to determine whether eliminating infes- tation with $T$. vaginalis may reduce the incidence of cervical carcinoma. A potential diagnostic test could be developed by testing for both serum anti- $T$. vaginalis as well as antiearly (E) and late (L) proteins of HPV types 16 and 18 antibodies.

We are grateful to Dr Chantapong Wasi of Mahidol University, Thailand, for the sera from cervical cancer patients. The above Thailand, for the sera from cervical cancer patients. The above Singapore Turf Club.

1 zur Hausen $\mathrm{H}$. Human genital cancer: synergism. between two virus infections or synergism between a virus infection and initiating events. The Lancet 1982;1370-2.

2 Low SH, Thong TW, Ho TH, et al. Prevalence of human papillomavirus types 16 and 18 in cervical carcinomas: A study by dot and southern blot hybridization and the polymerase chain reaction. fapan $\mathcal{F}$ Cancer Res 1990;81: 1118-23.

3 Berggren O. Association of carcinoma of the uterine cervix and Trichomonas vaginalis infestations. Am $\mathcal{f}$ Obstet Gynec 1969;105:166-8.

4 Meisels A. Dysplasia and carcinoma of the uterine cervix IV. A correlated cytologic and histologic study with special emphasis on vaginal microbiology. Acta Cytol 1969;13: 224-31.

5 Towbin H, Staehelin T, Gordon G. Electrophoretic transfer of proteins from polyacrylamide gels to nitrocellulose of proteins from polyacrylamide gels to nitrocellulose
sheets: Procedure and some applications. Proc Natl Acad Sheets: Procedure and

6 Garber GE, Proctor EM, Bowie WR. Immunogenic proteins of $T$. vaginalis as demonstrated by the immunoblot technique. Infect Immun 1986;51:250-3

7 Hollander DH. Colonial morphology of Trichomonas vaginalis in agar. $\mathcal{F}$ Parasitol 1976;62:826-8.

8 Dillner J, Lenner P, Lehtinen M, et al. A population-based seroepidemiological study of cervical cancer. Cancer Res 1994;54:143-141.

9 Lim KB, Thirumoorthy T, Nadarajah M, et al. Endocervical chlamydial infection in women attending a sexually-transmitted disease clinic in Singapore. Singapore Med $¥$ 1989;30:167-9.

10 Peterson KP, Alderete JF. Host plasma proteins on the surface of pathogenic Trichomonas vaginalis. Infect Immun face of pathogen

11 Naguib SG, Lundin F, Davis HJ. Relations of various epidemiologic factors to cervical cancer as defined by a screening program. Obstet Gynec 1966;28:451-9.

12 Brandonisio O, Restaino E, Sinigaglia E, et al. Vaginal trichomoniasis and precancerous state of the cervix. Biomed Lett 1991;46:39-43.

13 Hollander DH, Tysor JS. Isolation of stable clone of the ameboid-adherent (AA) variant of Trichomonas vaginalis. $\mathcal{F}$ Parasit 1987;73:1074-5.

14 Rasmussen SE, Nielsen MH, Lind I, et al. Morphological studies of the cytotoxicity of Trichomonas vaginalis to normal human vaginal epithelial cells in vitro. Genitourin Med 1986;62:240-6.

15 Alderete JF, Garza GE. Identification and properties of Trichomonas vaginalis proteins involved in cytoadherence. Infect Immun 1988;56:28-33.

16 Frost JK, Honigberg BM, McClure MT. Intracellular Trichomonas vaginalis and Trichomonas gallinae in natural and experimental infections. $f$ Parasitol 1961;47: 302-3.

17 Garber GE, Lemchuk-Favel LT, Bowie WR. Isolation of a cell-detaching factor of Trichomonas vaginalis. $\mathcal{F}$ Clin Microbiol 1989;27:1548-53.

18 Bozner P, Demes P. Proteinases in Trichomonas vaginalis and Tritrichomonas mobilensis are not exclusively of cysteine type. Parasitol 1991;102:113-5.

19 Matrisian LM, McDonnell S, Miller DB et al. The role of matrix metalloproteinase stromelysin in the progression of squamous cell carcinomas. Am $\mathcal{F} \mathrm{Med}$ Sci 1991;302: of squamous

20 Mason PR, Gwanzura L. Reduced lymphocyte responses to mitogens in natural and experimental trichomoniasis. Infect Immun 1990;58:3553-7.

21 Koutsky LA, Kiviat NB. Genital infectious agents and invasive cervical cancer. Lancet 1993;342:184-5.

22 Pindak FF, de Pindak MM, Hyde BM et al. Acquisition and retention of viruses by Trichomonas vaginalis. Genitourin Med 1989;65:366-71.

23 Street DA, Wells C, Taylor-Robinson D et al. Interaction between Trichomonas vaginalis and other pathogenic micro-organisms of the human genital tract. $\mathrm{Br} \mathcal{J}$ Vener Dis 1984;60:31-8.

24 Khoshnan A, Alderete JF. Multiple double-stranded RNA segments are associated with virus particles infecting segments are associated with virus particles
Trichomonas vaginalis. $\mathcal{F}$ Virol 1993;67:6950-5.

25 Alderete JF, Kasmala E, Metcalfe E, et al. Phenotypic variation and diversity among Trichomonas vaginalis isolates and correlation of phenotype with trichomonal virulence and correlation of phenotype with trichomon

26 Franco EL. Viral etiology of cervical cancer: A critique of the evidence. Rev Infect Dis 1991;13:1 195-206

27 Rodgerson EB. Vulvovaginal papillomas and Trichomonas vaginalis. Obstet Gynaecol 1972;40:327-33. 